Two further groups might be more susceptible to the effects of T.V. The first comprises immature individuals of low selfesteem but high expectations, still dependent but unable to trust, aware that they cannot stand alone, and greatly needing a non-demanding lead which gives them, however briefly, a sense of competence and direction. The second group comprises normal persons who have been involved in corporate violence. In this category are small groups of delinquents who, when examined separately, seem normal but in company can stimulate one another in circular fashion and may do an immense amount of damage. Also in this second group are people who follow and join in the sometimes appalling violence of their spouses, lovers, friends, or political leaders, misled, despite their seeming normality and previously inoffensive characters, by a gradual process of familiarization and acceptance.

If it is people such as these who are specially liable to suffer harm from watching violent scenes on television, their protection poses us all with a dilemma. Have we a duty to shield immature and inadequate adults just as we rightly protect our children ? Or is it a self-defeating course to try to protect people from inevitable stresses, temptations, and unpleasant experiences instead of helping them face these things and thus strengthen their characters? In the development of the ordinary boy or girl, for instance, there comes a stage at which wise parents look the other way and let them be shocked, because they are beginning to develop the

\section{Cardiac Hazards of Routine Investigations}

While thorough investigation is one of the cornerstones of clinical medicine, routine techniques can occasionally result in disaster. Attention has recently been drawn to the cardiovascular hazards of commonly performed investigations involving endoscopy and contrast radiography.

Most types of endoscopy have at some time been shown to provoke cardiac arrhythmias or electrocardiographic signs of myocardial ischaemia in susceptible patients. G. F. Fletcher and his colleagues encountered three cases of sudden and fatal cardiac arrest among a total of 1,800 patients having routine sigmoidoscopy. ${ }^{1}$ An electrocardiographic study was therefore made among 100 patients undergoing this investigation. Arrhythmias, mostly ectopic beats and none serious, were encountered in $40 \%$ of the patients with known cardiac disorders and in only $17 \%$ of the remaining 60 patients. Myocardial infarction and arrhythmias have been observed to follow gastroscopy ${ }^{23}$ as well, though such occurrences are extremely rare. Cardiac arrest and arrhythmias during diagnostic endoscopy are seen mainly in patients over the age of 50 with heart disease, though it is important to remember that large numbers of gastroscopies have been undertaken in the very elderly without mishap. ${ }^{4}$ Bronchoscopy or even simple endotracheal intubation has also been shown to induce arrhythmias, whether performed under local or general anaesthesia. ${ }^{56}$ The introduction of general anaesthesia complicates matters, because during bronchoscopy the patient is intermittently deprived of his ventilation and rendered hypoxaemic. Post-anaesthetic hypoxaemia too must also increase the risk of any procedure to a patient with coronary artery disease. capacities to deal with such things and because their ability to learn and adjust is intact. Unfortunately society contains a large proportion of individuals whose immaturity seems lasting rather than self-limiting, whose surroundings do little to help them grow up, and who would pay little attention to a wise parent even if one was standing by. Public media of $\frac{\pi}{\mathbb{Q}}$ communication inevitably make some compromises and in $\stackrel{\varrho}{c}$ doing so they should consider our weaker members. Whether $\stackrel{\vec{\Rightarrow}}{\vec{\prime}}$ they are making the right compromise at present is certainly arguable. What no one should do is to fly in the face of common sense while pleading that more research is neededhowever desirable that may be in itself.

In our readiness to find acceptable scapegoats for social $\stackrel{\mathbb{2}}{2}$ embarrassments we may pay too little attention to the potential value of television. F. Wertham ${ }^{5}$ has remarked that this $\overrightarrow{0}$ particular school for violence never teaches that violence in $\overrightarrow{\vec{J}}$ itself is something reprehensible. Yet that is something it $\vec{\omega}$ surely could do. The millions spent on T.V. advertising are evidence that tastes can be shaped.

${ }^{1}$ Himmelweit, H. T., Oppenheim, A. N., Vince, P., Television and the of Child, 1958. London, Oxford University Press. 2 Schramm, W., Lyle, J., and Parker, E. B., Television in the Lives of $\overrightarrow{\mathrm{N}}$

3 Halloran, J. D., The Effects of Mass Communication, With Special 음 Reference to Television, 1964. Leicester University Press.

- Halloran, J. D., Attitude, Formation, and Change, 1967. Leicester $\overrightarrow{0}$ University Press.

$s$ Wertham, F., A Sign for Cain, 1966. New York, Macmillan.

Patients undergoing diagnostic radiography occasionally suffer cardiovascular complications. When the investigations $\frac{\mathscr{Q}}{\mathbb{Q}}$ include cardiac catheterization and cardiography such prob- $\mathbb{Q}$ lems are to be expected, ${ }^{7}$ and full facilities are presumably $\overrightarrow{\overrightarrow{0}}$ always available for their correction. But more modest studies 3 may sometimes be accompanied by similar complications. In one report ${ }^{8}$ of a national survey carried out in the United Kingdom the incidence of severe reactions during intravenous pyelography was estimated to be around $0.02 \%$. Of four deaths noted during five years, the main feature was hypo- $\frac{5}{3}$ tensive collapse leading to cardiac arrest. The patients were in the 50-60 age group and two were known to have cardio- $\frac{0}{3}$ vascular disease. Hypotensive collapse alone was noted in $\mathrm{O}$ a further 23 patients, and oxygen, intravenous hydrocortisone ${ }_{N}^{J}$ (often requiring frequent repetition), and adrenaline were $\curvearrowright$ found to be the most effective therapy. Some clinicians may, however, be reluctant to give intravenous adrenaline to an elderly hypotensive patient and prefer to rely on steroids. N Hypotension appears to have occurred either during injection ${ }_{0}^{\omega}$ of contrast media or within the next 15 minutes. A preliminary test dose of the medium gave no reliable information $\frac{0}{0}$ about subsequent adverse reactions. Similar problems $\stackrel{\oplus}{\oplus}$ occurred after intravenous cholangiography and angiography.

When cardiac arrest occurs the most likely arrhythmia to be present is ventricular fibrillation. Cardiac massage and $\underset{\mathbb{D}}{\mathbb{D}}$

Fletcher, G. F., Earnest, D. L., Shuford, W. F., and Wenger, N. K., Archives of Internal Medicine, 1968, 122, 483.

2 Katz, D., and Selesnick, S., Gastroenterology, 1957, 33, 650. Palmer, E. D., and Witts, C. W.
Association, 1957, 164, 2012 .

Association, 1957, 164, 2012.
s Smith, J. N., and Clifton, J. A., Gastroenterology, 1956, 30, 676.
s Burman, S. O., and Gibson, T. C., Annals of Surgery, 1963, 157, $134 . \frac{\mathrm{C}}{\mathrm{C}}$

Burman, S. O., and Gibson, T. C., Annals of Surgery, 1963, 157, 134.

- Van Nouhuys, F., Thorax, 1965, 20, 467.

Co-operative Study on Cardiac Catheterisation. Circulation, 1968, 37, Suppl. 3.

8 Ansell, G., Clinical Radiology, 1968, 19, 175. 
ventilation alone may occasionally restore normal rhythm after cardiac arrest, but the full process of rhythm identification and defibrillation, or pacing in the case of asystole, is usually required. When a defibrillator is not available and the heart is in ventricular fibrillation, intravenous procaine amide or lignocaine with continued cardiac massage and ventilation may occasionally restore sinus rhythm and should always be tried. The analeptic drugs frequently found in resuscitation trays are of little or no value.

The patients most likely to experience serious cardiac arrhythmias, periods of hypotension, or myocardial infarction during these diagnostic procedures are those over the age of 50 knəwn to have heart disease, particularly coronary artery disease or hypertension. A basic precaution would be to ensure that all medical and ancillary staff are well tutored in the principles and practice of resuscitation. ${ }^{9}$

Clearly the risks of such disasters are very small, and many clinicians will have carried out the investigations mentioned for many years without encountering such problems. It therefore would be unrealistic to suggest that these investigations should be undertaken only where complete resuscitative facilities are available. An awareness of the possible hazards, careful selection of patients, and a knowledge of resuscitative techniques should provide adequate safeguard against mishap.

\section{Congenital Cardiac Malformation and Facial Weakness}

In 1967 Glen Cayler" reported an "epidemic" of the hitherto undescribed association of ventricular septal defect with a persistent unilateral facial paralysis involving only the mentalis and the quadratus labii inferioris muscles, which are supplied by a single branch of the facial nerves. The paralysis did not cause facial asymmetry and was apparent only when the child cried. The first case was seen in June 1966, and four further cases of the association of this form of paralysis with congenital heart malformation were seen before the end of the year and were all born within a 100 miles of Sacramento. Three had ventricular septal defect, and Cayler now reports 9 further cases ${ }^{2}$ from the same area, making 14 in all, of whom 7 were born in Sacramento itself. Three had a full tetralogy of Fallot, 8 had ventricular septal defect by itself or with other heart lesions, and 1 had mild valvar pulmonary stenosis. Congestive failure developed in 8. The sex distribution was 5 males to 9 females. All cases were sporadic and none of 19 sibs had any malformation. In addition to the main pair of malformations, 3 patients were mentally retarded, and 2 of these were microcephalic ; 4 had skeletal malformations, including 2 with radial aplasia ; 1 had an imperforate anus, 1 anal stenosis, and 2 umbilical herniae ; and 1 had aplasia of the right kidney and a branchial cleft anomaly.

The pregnancies were unremarkable, with no infectious disease; nine of them started in the summer months.

Cayler, G. G., Pediatrics, 1967, 40, 666.

'Cayler, G. G., Archives of Disease in Childhood, 1969, 44, 69.

: Holt, M., and Oram, S., British Heart fournal, 1960, 22, 236.

' Feingold, M., in Year Book of Pediatrics (1966-1967), 1967, p. 328. ed. S. S. Gellis. Chicago, Year Book Medical Publishers.
Chromosome studies showed no specific changes, but it was considered that there was an excess of breaks present.

This association of malformations is remarkable and worth looking out for. If an infant shows a weakness of the lower lip when crying it suggests that a careful examination should $\stackrel{\text { W }}{\longrightarrow}$ be made of the heart. The cause of the condition remains $\frac{3}{\infty}$ obscure. Cayler notes, however, the embryonic proximity of $\frac{\varrho}{C}$ the hyoid arch and the developing heart in the 6-mm. embryo and also the known association ${ }^{34}$ of aplasia of the radius with atrial and ventricular septal defects.

\section{Donors for Transplants}

No change is to be made in the law governing human transplantation. Sir Hector MacLennan's advisory group, ${ }^{1}$ set ${ }^{\circ}$ up in January, reported ${ }^{2}$ earlier this week, and Mr. Crossman has let it be known that the Government intends to take no $\vec{N}$ action until there is a clearer consensus of medical and public $ᄋ$ opinion.

In its report the advisory group agreed that the supply of organs for transplantation ought to be increased-“ a reputable and, in skilled hands, proven technique of saving life $\vec{\varphi}$ should not be held back by obsolete law or by lack of information." The group also agreed that the public had a right $\square$ to safeguards, and it recommended that the death of a potential donor should be certified by " two doctors, one of whom should be at least five years registered, each independent of the transplant team and without regard to the possibility of $\mathbb{Q}$ a transplant." The report was adamant that transport of $\overrightarrow{\vec{\overrightarrow{ }}}$ patients between hospitals for the purposes of transplantation must be restricted to moving the recipient.

The advisory group did not agree on recommendations for changes in the law. Six of the eleven members favoured contracting out. They would require an effective mechanism for recording objection and an obligation on transplant teams $\frac{0}{7}$ to search the register. With these provisos surgeons should 3 be able to remove organs "unless there were definite indica- of tions that the deceased had objected." The five others advised limited amendment of the present law. The Human Tissue $\mathrm{Act}^{3}$ provides that the person lawfully in possession $\mathcal{N}^{\circ}$ of a body may authorize removal of parts of it if, having $D$ made such reasonable inquiry as may be practicable, he has no reason to believe there was any objection before death by $N$ the deceased or after it by any surviving relative. These $\underset{\omega}{\mathrm{N}}$ phrases should be redefined, said the minority report: the hospital authority should be specified as lawfully in possession of the body until it was claimed by the executors or next $\stackrel{\varnothing}{\varnothing}$ of kin, and the persons with a right to be consulted and the + scope of the inquiry should also be defined. More publicity should be given to the procedures under the existing law; $\underset{\mathbb{D}}{\mathbb{D}}$ efforts should be made to identify potential donors or objec-

1 The membership of the advisory group is as follows: Sir Hector MacLennan (chairman), Professor R. Y. Calne, Mr. D. Currie, Rev. O Professor S. R. Dunstan, Mr. J. Garfield, Professor W. S. Peart, O Dame Muriel Powell, Dr. G. L. B. Thurston, Miss Katharine Whitehorn, Sir Michael Woodruff, and Baroness Wootton of Abinger.

- Advice from the Advisory Group on Transplantation Problems on the Question of Amending the Human Tissue Act 1961. London, H.M.S.O. 1969. 1s. 3d.

3 Human Tissue Act, 1961.

- Calne, R. Y., British Medical fournal, 1969, 2, 566. 